\title{
Superiority of spacer/mask topical anaesthetic compared with conventional spray and gargle method for fibreoptic bronchoscopy
}

\author{
RC BALKISSOON MD, L CLELLAND RN, L WHITEHEAD MD, MT NEWHOUSE MD \\ Firestone Regional Chest and Allergy Unit, St Joseph's Hospital, Hamilton, Ontario
}

RC Balkissoon, L Clelland, L Whitehead, MT NEWHOUSE. Superiority of spacer/mask topical anaesthetic compared with conventional spray and gargle method for fibreoptic bronchoscopy. Can Respir J 1996;3(3):176-180.

OBJECTIVE: To compare the safety and efficacy of a new spacer-oral nasal mask device with those of the standard needle nozzle spray method for the delivery of aerosolized lidocaine to the upper airway for pre-bronchoscopic anaesthesia in a tertiary care hospital.

DESIGN: Single-blind randomized control trial.

SETTING: University affiliated tertiary care hospital, ambulatory care bronchoscopy unit.

SUBJECTS: Thirty consecutive consenting patients referred for fibreoptic bronchoscopy for various indications.

INTERVENTION: Thirty randomized subjects received $150 \mathrm{mg}$ of topical $1 \%$ aerosolized lidocaine via standard long needle nosed applicator (group A) or via a new oral/ nasal mask with spacer device (group B). Bronchoscopists, blinded as to the preprocedure topical anaesthetic method used, gave additional topical lidocaine at their discretion. MEASUREMENTS: The study nurse recorded the total dose of lidocaine $(\mathrm{mg})$, timing of the procedure (s), cough frequency expressed as coughs per minute (c/min), vital signs, time for return of gag reflex and patients' subjective comments.

RESULTS: Fifteen patients were randomized to each group. The lidocaine dose required for insertion through the vocal cords (mean $\pm \mathrm{SD}$ ) was $282.6 \pm 66.3 \mathrm{mg}$ in group $\mathrm{A}$ and $203.3 \pm 70.6 \mathrm{mg}$ in group $\mathrm{B}(\mathrm{P}<0.005)$. Total lidocaine dose required for the procedure was $330.6 \pm 70.2 \mathrm{mg}$ in group $\mathrm{A}$ and $256.6 \pm 75 \mathrm{mg}$ in group $\mathrm{B}(\mathrm{P}<0.01)$. The mean time for passage of the bronchoscope from mouth entry to through the vocal cords was $82.7 \pm 54.5 \mathrm{~s}$ in group $\mathrm{A}$ and $110.5 \pm 64.4 \mathrm{~s}$ in group $\mathrm{B}(\mathrm{P}>0.1)$. The mean total time for the procedure was $699.7 \pm 377.5 \mathrm{~s}$ in group $\mathrm{A}$ and $697.2 \pm 409.1 \mathrm{~s}$ in group B (not significant). The mean cough frequency was $8.2 \pm 6.1 \mathrm{c} / \mathrm{min}$ in group $\mathrm{A}$ and $7.0 \pm 5.7 \mathrm{c} / \mathrm{min}$ in group B (not significant). There were no statistically significant differences in heart rate, in return of gag reflex time or in complication rate between the two groups.

CONCLUSIONS: A statistically significant reduction in the dose of lidocaine is required to achieve equivalent topical anaesthetic for bronchoscopy with a new mask and spacer device compared with a more conventional method. Since no other variables related to the procedure showed a significant difference, the new method appears to be superior to the previous method. (Pour résumé voir page 177)

Key Words: Anaesthesia, Aerosols, Bronchoscopy

Correspondence: Dr RC Balkissoon, National Jewish Center for Immunology and Respiratory Medicine, 1400 Jackson Street, Denver, CO 80206, USA. Telephone 303-398-1520,fax 303-398-1452, e-mail balkissoonr@njc.org 


\section{Supériorité de la technique d'anesthésie locale par masque avec dispositif d'espacement com- parée à la technique d'anesthésie classique par pulvérisation et gargarisme pour pratiquer une fibroscopie bronchique}

OBJECTIF : Comparer un nouveau système de masque oronasal muni d'un dispositif d'espacement avec la méthode classique de vaporisation par cône applicateur, sur le plan de la sûreté et de l'efficacité, pour administrer de la lidocaïne en aérosol dans les voies respiratoires supérieures en vue d'une anesthésie prébronchoscopique dans un hôpital de soins tertiaires.

MODÈLE : Essai contrôlé randomisé à simple insu.

CONTEXTE : Hôpital de soins tertiaires affilié à une université, unité des soins ambulatoires pour la bronchoscopie.

SUJETS : Une série de trente patients consentants adressés pour une fibroscopie bronchique pour des indications variées.

INTERVENTION : Trente sujets randomisés ont reçu $150 \mathrm{mg}$ de lidocaïne à $1 \%$ en aérosol administrée localement à l'aide d'un applicateur nasal classique (groupe $\mathrm{A}$ ) ou par un nouveau système de masque oro-nasal muni d'un dispositif d'espacement (groupe B). La prémédication a été faite suivant l'une des deux méthodes à l'insu des bronchoscopistes qui pouvaient, à discrétion, administrer localement des doses supplémentaires de lidocaïne.

MESURES : L'infirmière de l'essai a consigné la dose totale (mg) de lidocaïne administrée, le temps (s) de l'intervention, la fréquenc)e de la toux exprimée en nombre de fois par minute $(\mathrm{t} /$ minute, les signes vitaux, l'heure de réapparition du réflexe pharyngé et les commentaires subjectifs du patient.

RÉSULTATS : Quinze patients ont été randomisés en deux groupes. La dose de lidocaïne requise pour l'insertion du bronchoscope à travers les cordes vocales (moyenne \pm écart-type) était de $282,6 \pm 66,3 \mathrm{mg}$ dans le groupe A et de 203,3 $\pm 70,6 \mathrm{mg}$ dans le groupe $\mathrm{B}(\mathrm{P}<0,005)$. La dose totale de lidocaïne requise pour l'intervention était de $330,6 \pm 70,2 \mathrm{mg}$ dans le groupe A et de $256,6 \pm 75$ $\mathrm{mg}$ dans le groupe $\mathrm{B}(\mathrm{P}<0,01)$. Le temps moyen de passage du bronchoscope de la bouche jusqu'à la traversée des cordes vocales était de $82,7 \pm 54,5 \mathrm{~s}$ dans le groupe A et de 110,5 $\pm 64,4 \mathrm{~s}$ dans le groupe $\mathrm{B}(\mathrm{P}>0,1)$. Le temps total moyen pour l'intervention était de $699,7 \pm 377,5 \mathrm{~s}$ dans le groupe A et de $697,2 \pm 409,1 \mathrm{~s}$ dans le groupe $\mathrm{B}$ (non significatif). La fréquence moyenne de la toux était de $8,2 \pm 6,1 \mathrm{t} /$ minute dans le groupe $A$ et de $7,0 \pm 5,7 \mathrm{t} /$ minute dans le groupe B (non significatif). Il n'y avait aucune différence significative dans le rythme cardiaque, la réapparition du réflexe laryngé ou le taux de complications entre les deux groupes.

CONCLUSIONS : Le nouveau système de masque muni d'un dispositif d'espacement permet de réduire considérablement la dose de lidocaïne requise pour procéder à une anesthésie prébronchoscopique locale équivalente à celle pratiquée par une méthode plus classique. Puisque l'on a observé aucune différence dans les autres variables associées à l'intervention, la nouvelle méthode d'anesthésie semble donc supérieure à celle utilisée antérieurement.
$\mathrm{F}$ ibreoptic bronchoscopy is indicated in numerous clinical scenarios and provides a vital diagnostic tool in current respiratory medicine. Unfortunately, considerable patient discomfort is associated with this procedure. Many patients object to the unpleasant taste of lidocaine, and to coughing and gagging during the gargling and spraying of the oropharynx. This standard spray method often delays the starting of the procedure due to marked patient discomfort and anxiety. This may lead to a prolonged, poorly tolerated procedure with suboptimal sample collection. Furthermore, patients who have suffered through one procedure are reluctant to repeat the procedure when necessary.

Numerous authors have evaluated various techniques for anaesthetizing the upper airway with aerosolized or nebulized lidocaine (1). Administration of lidocaine by nebulizer has been advocated, but this method requires large doses of medication and has not been very efficient or effective (2-4). Clark and Pond (5) have recently described atomization of the drug.

Aerosol therapy with beta-agonists using a metered dose inhaler (MDI) (especially with holding chamber) is 2.5 to six times as efficient as continuous nebulization for bronchodilation in asthmatics $(6,7)$. Other investigators have developed new methods of efficiently 'targeting' the respiratory tract (eg, spacer devices) (8).

This study compared the dose of lidocaine, the time required and the subject tolerance for a new spacer/mask device versus a conventional spray appli- cator device in the delivery of aerosolized lidocaine to the oropharynx before bronchoscopy.

\section{PATIENTS AND METHODS}

Subjects: Thirty consecutive subjects were entered into the study. Excluded subjects had contraindications to one or more protocol medications (ie, atropine, midazolam and lidocaine). All subjects were informed of all procedures and signed appropriate consent forms. The Hospital Ethics Committee for Human Research approved the protocol.

Premedication: Subjects received atropine ( 0.4 to 0.6 $\mathrm{mg} / \mathrm{s}) 30 \mathrm{mins}$ before the procedure. After subjects consented to participate in the study, all patients received midazolam (5 mg intramuscularly or $2 \mathrm{mg}$ intravenously) just before starting the procedure.

Randomization and blinding: A nurse research assistant using a random numbers table assigned subjects to the standard spray method (group A) or to the spacer/mask method (group B). Subjects were then given the topical anaesthetic by the nurse before the physician entered the endoscopy suite. The bronchoscopist was therefore blinded to the anaesthetic technique used.

Procedure: Subjects received $150 \mathrm{mg}$ (15 actuations) of $1 \%$ lidocaine (Xylocaine; Astra) $(10 \mathrm{mg} / \mathrm{mL})$ directed onto the pharynx via the standard spray device or the new spacer/ mask device. The standard method used a standard aerosol MDI with a long nosed metal applicator (Figure 1) to spray the posterior pharynx and the vo- 


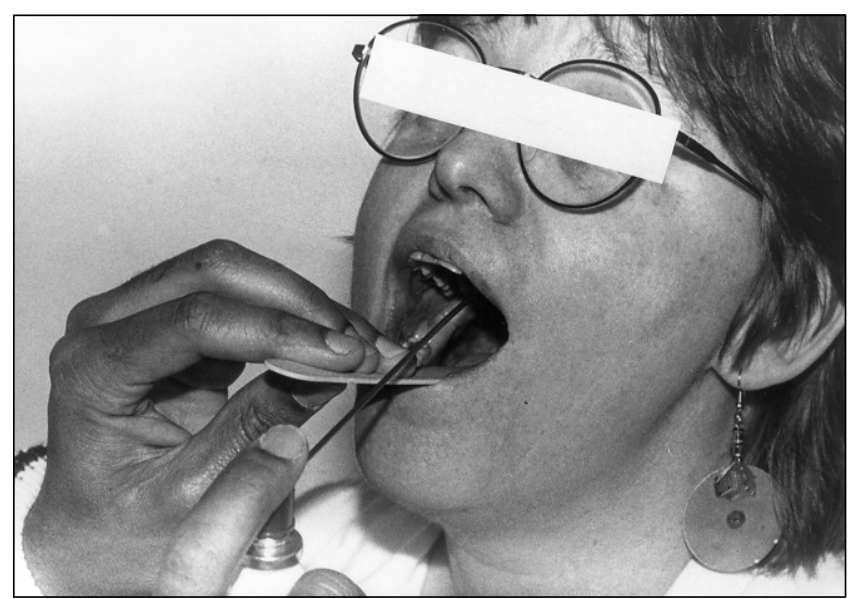

Figure 1) Standard method uses an aerosol metered dose inhaler with a long nosed metal applicator

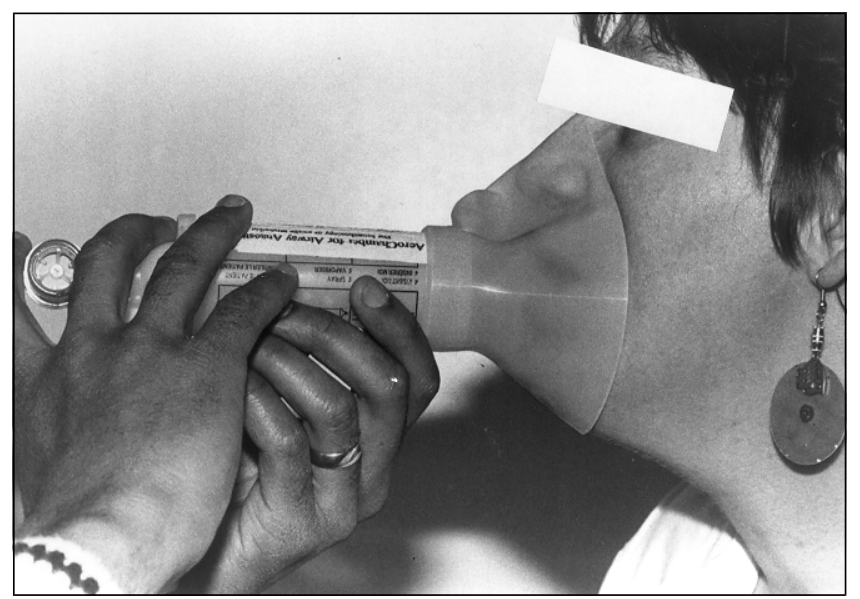

Figure 2) New method places the spacer/mask device over the mouth and nose

cal cords. If the patient started to cough during the application the nurse would wait until coughing ceased before giving the next actuation. Subjects who received lidocaine using the new method placed the spacer/mask device over their mouth and nose (Figure 2). The oral nasal mask allowed the patients to use the open mouth technique for breathing in the medication. With each actuation of the device, subjects were directed to take rapid deep breaths through their widely open mouth to total lung capacity to achieve relatively high inspiratory flow rates (approximately $60 \mathrm{~L} / \mathrm{min}$ ). They were monitored during the procedure to ensure that they did not inhale via the nose. With the new technique, the lidocaine MDI was actuated at $10 \mathrm{~s}$ intervals, thus delivering the $150 \mathrm{mg}$ of lidocaine over approximately 3 mins.

The bronchoscope was introduced through a hollow bite block between the teeth and passed through the vocal cords. The bronchoscopist used additional $4 \%$ lidocaine $(40 \mathrm{mg} / \mathrm{mL})$, instilled directly onto the vocal cords through the bronchoscope, as needed, to
TABLE 1

Patient profile

\begin{tabular}{lcc}
\hline & Spray method & $\begin{array}{c}\text { Mask/spacer } \\
\text { method }\end{array}$ \\
\hline Male/female & $10 / 5$ & $8 / 7$ \\
Age (mean years) & 78 & 60 \\
Nonsmokers/smoker & $4 / 11$ & $4 / 11$ \\
\hline
\end{tabular}

TABLE 2

Indications for bronchoscopy

\begin{tabular}{lcc}
\hline & Spray method & $\begin{array}{c}\text { Mask/spacer } \\
\text { method }\end{array}$ \\
\hline Cough & 2 & 4 \\
Hemoptysis & 4 & 4 \\
Abnormal radiograph & 7 & 7 \\
Other & 2 & 0 \\
Total & 15 & 15 \\
\hline
\end{tabular}

TABLE 3

Procedures performed during bronchoscopy

\begin{tabular}{lcc}
\hline & Spray method & $\begin{array}{c}\text { Spacer/mask } \\
\text { method }\end{array}$ \\
\hline $\begin{array}{l}\text { Washings for } \\
\text { cytology/microbiology }\end{array}$ & 6 & 5 \\
$\begin{array}{l}\text { Washings and brushings } \\
\text { Washings, brushings and }\end{array}$ & 4 & 6 \\
$\quad$ biopsy & 5 & 4 \\
Total & 15 & 15 \\
\hline
\end{tabular}

control cough and laryngospasm. Past the vocal cords the procedure was carried out in the usual manner with instillation of $1 \%$ topical lidocaine solution applied through the bronchoscope, $1 \mathrm{~mL}$ at a time, as required to minimize cough. The study nurse recorded the total dose of lidocaine required to allow the bronchoscope to be passed through the vocal cords, as well as the total dose for the whole procedure.

Outcomes: The primary outcome measure was the total lidocaine dose required $(\mathrm{mg})$ to complete the procedure. Secondary outcome measures included the lidocaine dose required to pass the bronchoscope through the vocal cords $(\mathrm{mg})$, the time from introduction of the bronchoscope into the mouth to the bronchoscope passage through the vocal cords (s), total procedure time (s) and cough frequency (c/min). The number of coughs and various times were recorded by the nurse research assistant using a manual counter and stopwatch.

Other outcomes evaluated during the procedure were maximum change in heart rate and complications (bleeding, pneumothorax, etc). Patients were also asked for any general comments regarding any discomfort from the procedure.

Data analysis: The arithmetic means of the total dose 
of lidocaine topical anaesthetic required, the mean time to pass through the vocal cords, mean cough frequency and mean total number of coughs were compared between the two groups using unpaired $t$ test analysis.

\section{RESULTS}

Subject characteristics: There were 15 subjects randomized to each group. There were no significant differences with regard to sex, age or smoking history (Table 1). No significant differences were detected between groups with respect to indications for bronchoscopy (Table 2) or to the type of procedures performed (Table 3).

Lidocaine dose: The lidocaine dose required for insertion of the bronchoscope through the vocal cords (mean $\pm \mathrm{SD}$ ) was $282.7 \pm 66.4 \mathrm{mg}$ in group $A$ and $203.3 \pm 70.7 \mathrm{mg}$ in group $B(P<0.005)$. Total lidocaine dose required for the procedure was $330.7 \pm 70.2 \mathrm{mg}$ in group $A$ and $256.7 \pm 75.7 \mathrm{mg}$ in group $B(P<0.01)$.

Length of time for procedure: The mean duration from the time the bronchoscope passed the lips until insertion through the vocal cords was $82.7 \pm 54.5 \mathrm{~s}$ in group $A$ and $110.5 \pm 64.4 \mathrm{~s}$ in group $B(P>0.1)$. The total time for the procedure was $699.7 \pm 377.5 \mathrm{~s}$ in group $A$ and $697.3 \pm 409.1 \mathrm{~s}$ in group $B(P>0.1)$ (Table 4).

Other parameters: Cough frequency was $8.2 \pm 6.2$ $\mathrm{c} / \mathrm{min}$ in group $A$ and $7.0 \pm 5.7 \mathrm{c} / \mathrm{min}$ in group $B(P>0.1)$. There were no statistically significant differences in changes in heart rate, in return of gag reflex or in complication rate between the two groups. Subjective comments about taste and tolerability of anaesthetic and bronchoscopy procedures were similar in the two groups.

\section{DISCUSSION}

Topical anaesthesia remains a fairly cumbersome and time consuming technique which, using our standard spray procedure, involves either applying lidocaine gel to the nasal airway for per nasal introduction and/or gargling $2 \mathrm{~mL}$ of unpleasant tasting $4 \%$ lidocaine solution in approximately $8 \mathrm{~mL}$ of water for per oral insertion of the bronchoscope. This is followed by blindly spraying a $1 \%$ solution onto the pharynx, epiglottis and vocal cords and then giving additional $4 \%$ lidocaine soIution $1 \mathrm{~mL}$ at a time directly onto the cords under direct vision through the bronchoscope.

Topical anaesthesia above and onto the cords usually requires the administration of up to $300 \mathrm{mg}$ of lidocaine, provided in $40 \mathrm{mg}$ aliquots $(40 \mathrm{mg} / \mathrm{mL})$. Ongoing topical anaesthesia of the lower respiratory tract generally requires an additional 100 to $300 \mathrm{mg}$ of $1 \%$ lidocaine, the larger doses for prolonged procedures such as fluoroscopically guided transbronchial biopsy (total maximum lidocaine dose $400 \mathrm{mg}$ over 20 to $30 \mathrm{mins}$ ). Gargling with and spraying unpleasant tasting lidocaine onto the oropharynx and upper airway causes many patients to gag and cough, which delays the start of the
TABLE 4

Comparison of primary outcomes for the two methods

\begin{tabular}{lccc}
\hline & $\begin{array}{c}\text { Spray } \\
\text { method }\end{array}$ & $\begin{array}{c}\text { Spacer/mask } \\
\text { method }\end{array}$ & P \\
\hline $\begin{array}{c}\text { Total lidocaine per } \\
\text { patient (mg) }\end{array}$ & $330.6 \pm 70.2$ & $256.7 \pm 75.7$ & 0.009 \\
$\begin{array}{c}\text { Lidocaine to pass } \\
\text { vocal cords (mg) }\end{array}$ & $282.7 \pm 66.4$ & $203.3 \pm 70.7$ & 0.003 \\
$\begin{array}{c}\text { Time to pass vocal } \\
\text { cords (s) }\end{array}$ & $82.7 \pm 54.5$ & $110.5 \pm 64.4$ & 0.22 \\
$\begin{array}{c}\text { Total procedure time } \\
\text { (s) }\end{array}$ & $700 \pm 378$ & $697.3 \pm 40.1$ & 0.98 \\
\hline
\end{tabular}

Data are mean $( \pm S D)$

procedure and creates significant patient anxiety. This anxiety may exacerbate coughing and gagging, leading to a prolonged poorly tolerated procedure with suboptimal sample collection. Patients who have suffered through one procedure are reluctant to repeat the procedure when needed.

The current project tested a unique spacer/mask delivery system to study patient acceptance, reduction of bronchoscope insertion time, total bronchoscopy time and anaesthetic dose requirements compared with a technique currently used by many bronchoscopists.

The new method attempted to anaesthetize the airway from the tongue to the periphery by taking advantage of dispersion of the droplet aerosol produced by these canisters via the spacer/mask device. The larger droplets in the aerosol spray (which contains particles of many sizes from approximately $30 \mathrm{~mm}$ down to 1 $\mathrm{mm}$ ) are more likely to be deposited in the upper respiratory tract and central airways because of high inspiratory flow rates that favour impaction, while the smaller particles (less than $5 \mathrm{~mm}$ ) are likely to be carried to more peripheral airways (9).

Thus the spacer/mask method should provide topical anaesthesia to the whole respiratory tract, from the mouth to the peripheral airways, depositing the majority of the dose in more proximal airways at the level of the gag and cough receptors. These receptors are located mainly in the pharynx and upper respiratory tract around the vocal cords and in the central airways of the lower respiratory tract (10). It was postulated that this spacer dispersed aerosol would be more evenly distributed to these receptors than would be the case with the nozzle spray method, thus providing effective topical anaesthesia with a smaller total dose. Minimizing total topical lidocaine dose is desirable because there are reported systemic side effects (11-13).

This study confirms that the spacer/mask device provides equivalent symptomatic benefit to the spray method with a $25 \%$ decrease in the total dose of lidocaine. No significant differences were observed between the two methods in terms of time to pass the endoscope through the cords, total time of the proce- 
dure, cough frequency or change in heart rate. The dose reduction translates into cost savings. The safety and ease of premedication with lidocaine using the new spacer/ mask method allows endoscopy nurses to readily perform this procedure, thus saving physician time.

We did not include data regarding the time taken to administer the 15 actuations of $1 \%$ lidocaine either via the standard or new method. Typically it took longer to use the standard method because the nurse would often have to wait for the patient to stop coughing between actuations. The spacer mask method caused very little cough response during the actuations. Because it was not possible to do this part of the study in a blinded fashion, we felt that there was significant potential for bias by the study nurse in terms of deciding when to resume giving the lidocaine using the standard method.

The nurse who gave the premedication anaesthetic also counted coughs using a manual counter. The fact that the nurse was not blinded to the type of premedication administered could theoretically lead to biased counting of coughs. No difference was noted between the two groups with respect to cough frequency, which could be interpreted to mean that there was no true difference between the two groups or that the nurses under-counted or over-counted coughs in one or the other group. Cough frequency was one of many measures recorded to compare patient tolerance of the procedure between the two treatment groups. Other measures such as change in heart rate, time to complete the procedure and subjective comments of patients indicate that patient tolerance was comparable between the two groups.

We did not measure serum lidocaine levels in this study. Previous studies $(4,13)$ have demonstrated that systemic serum levels of lidocaine are well below the recommended therapeutic range of 2 to $6 \mathrm{mg} / \mathrm{mL}$ when the lidocaine is delivered by ultrasonic nebulizer plus direct instillation of lidocaine onto the mucosa of the upper and lower airways. Total doses of lidocaine delivered to the airways were in the range of 450 to 540 $\mathrm{mg}$ in one study (4) and over $1600 \mathrm{mg}$ in another study

\section{REFERENCES}

1. Keane D, McNicholas WT. Comparison of nebulized and sprayed topical anaesthesia for fibreoptic bronchoscopy. Eur Respir J 1992;5:1123-5.

2. Middleton RM, Shah A, Kirkpatrick MB. Topical nasal anesthesia for flexible bronchoscopy. Chest 1991;99:1093-6.

3. Isaac PA, Barry JE, Vaughan RS, Rosen MB, Newcombe RG. A jet nebuliser for delivery of topical anaesthesia for the respiratory tract:

A comparison with cricothyroid puncture and direct spraying for fibreoptic bronchoscopy. Anaesthesia 1990;45:46-8.

4. Gove RI, Wiggins J, Stableforth DE. A study of the use of ultrasonically nebulized lignocaine for local anaesthesia during fibreoptic bronchoscopy. Br J Dis Chest 1985;79:49-59.
(13). These values are significantly higher than the maximum lidocaine doses used in our study (approximately $400 \mathrm{mg}$ ). It is unlikely that the dose of drug delivered to the tracheobronchial tree is higher with the spacer device because a significant portion of the dose is captured in the spacer device itself. We propose that the spacer device technique results in delivery of a more uniform distribution of the medication to the airways. Furthermore, neither group demonstrated evidence of lidocaine toxicity, particularly central nervous system excitation or depression, or cardiovascular compromise such as bradycardia or hypotension.

Although the patients' subjective comments regarding the actual anaesthetic procedure are the 'softest data', these comments are potentially the most useful clinical information as to whether the spacer/mask method offers any perceived symptomatic benefit to the patient. Not surprisingly, in this study there is little to distinguish the nature of these comments between the two groups because patients were anaesthetized with one method or the other and thus could not compare them.

\section{CONCLUSIONS}

This study demonstrated that initial topical anaesthesia delivered as a widely dispersed aerosol from a spacer/mask device resulted in the need for a reduced total dose of lidocaine to achieve equivalent cough control compared with a highly focused droplet spray directed against the pharynx. This suggests that the more dispersed aerosol spray is able to anaesthetize the posterior pharynx and fauces better than the older method. Since the primary outcome variable was the additional local anaesthetic necessary to achieve optimum cough control it is not surprising that no differences could be demonstrated in any of the other outcome measures.

ACKNOWLEDGEMENTS: We thank K Fields RN for her assistance with carrying out the bronchoscopies as well as collecting and recording data.

5. Clark G, Pond C. Adaption of the de Vilbiss Atomizer for the delivery of topical anesthesia. Nurse Anesthesia 1992;3:20-4.

6. Blake K, Hoppe M, Harman E, Hendeles L. Relative amount of albuterol delivered to lung receptors from a metered-dose inhaler and nebulizer solution. Chest 1992;101:309-15.

7. Calcone A, Afilalo M, Wolkove N, Kreisman H. A comparison of albuterol administered by metered dose inhaler (and holding chamber) or wet nebulizer in acute asthma. Chest 1993;104:835-41.

8. Dolovich MB, Newhouse MT. Aerosols. In: Middleton E, Reed CE, Ellis EF, Adkinson NF, Yunginger JW, Busse WW, eds. Allergy: Principles and Practice, 4th edn. St Louis: Mosby-Year Book, Inc, 1993:712-39.

9. Pavia $D$, Thomson ML. The fractional deposition of inhaled 2 
and $5 \mathrm{~mm}$ particles in the alveolar and tracheobronchial regions of the healthy human lung. Ann Occup Hyg 1976;19:109-14.

10. Barnes PJ, Basbaum CB, Nadel JA. Autoradiographic localization of autonomic receptors in airway smooth muscle: marked differences between large and small airways. Am Rev Respir Dis

1983;127:758

11. Kirkpatrick MB, Sanders RV, Bass JB. Physiologic effects and serum lidocaine concentrations after inhalation of lidocaine from a compressed gas-powered jet nebulizer. Am Rev Respir Dis 1987:136:447-9.

12. McAlpine LG, Thomson NC. Lidocaine-induced bronchoconstriction in asthmatic patients. Chest 1989;96:1012-5.

13. Berger R, McConnel JW, Phillips B, Overman TL. Safety and efficacy of using high-dose topical and nebulized anesthesia to obtain endobronchial cultures. Chest 1989;95:299-302. 


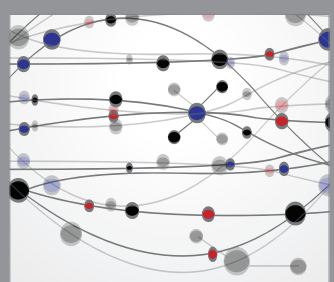

The Scientific World Journal
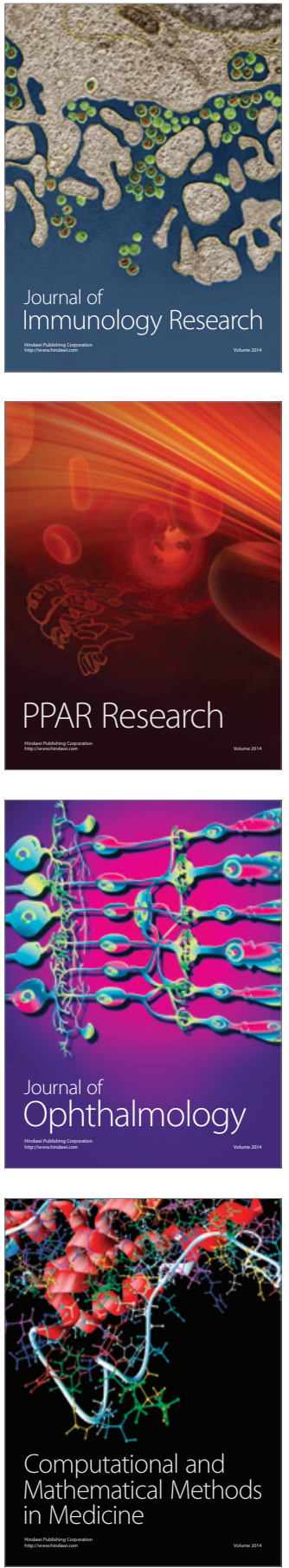

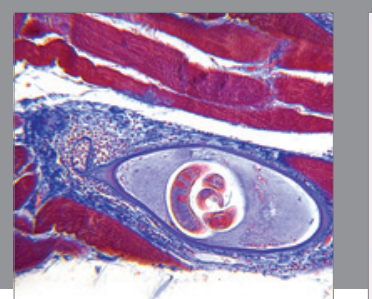

Gastroenterology Research and Practice

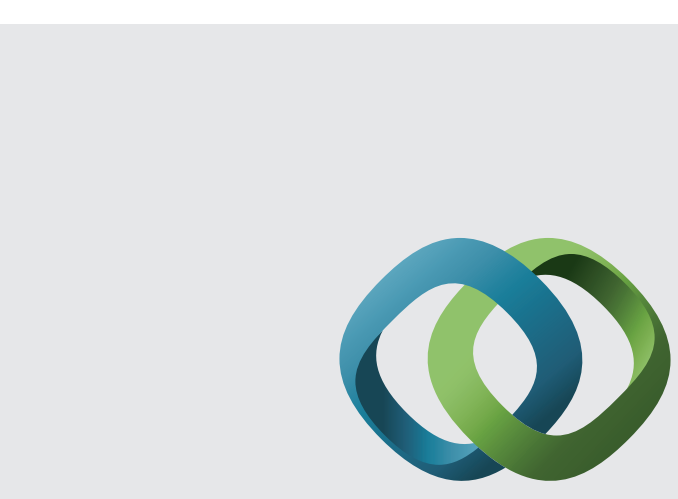

\section{Hindawi}

Submit your manuscripts at

http://www.hindawi.com
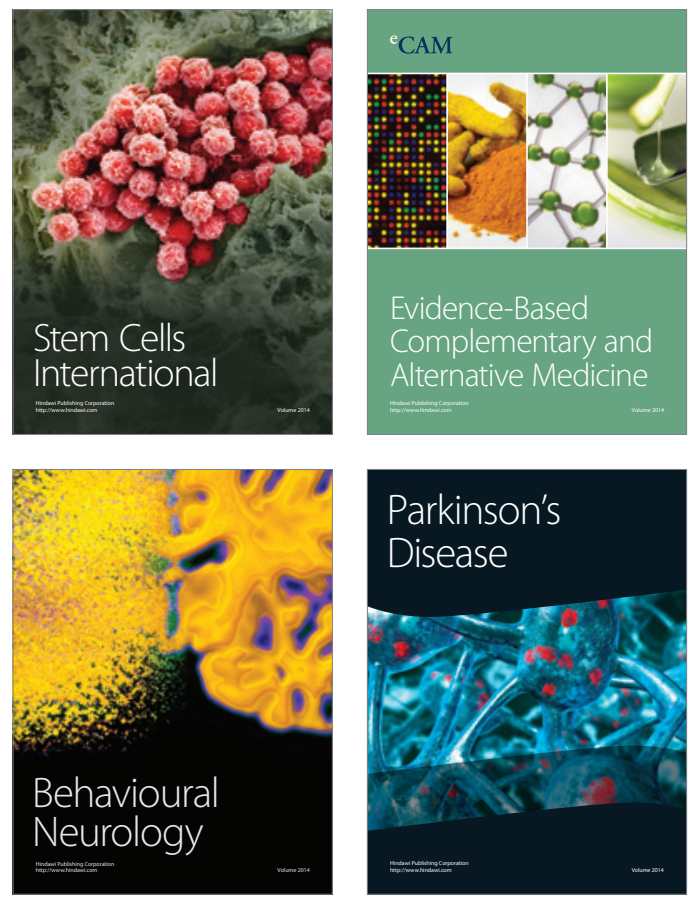
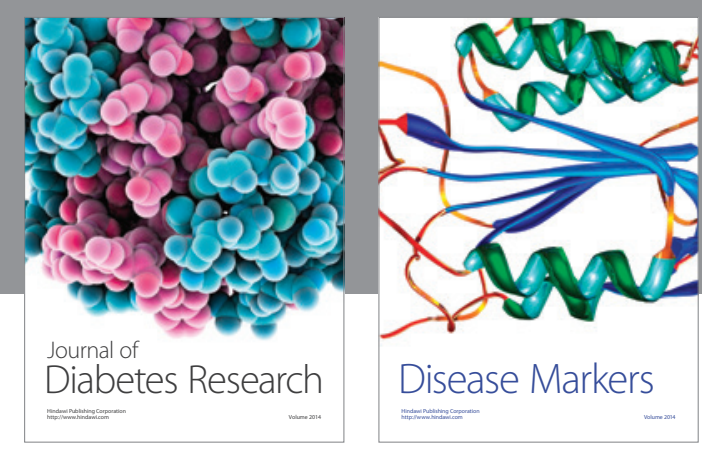

Disease Markers
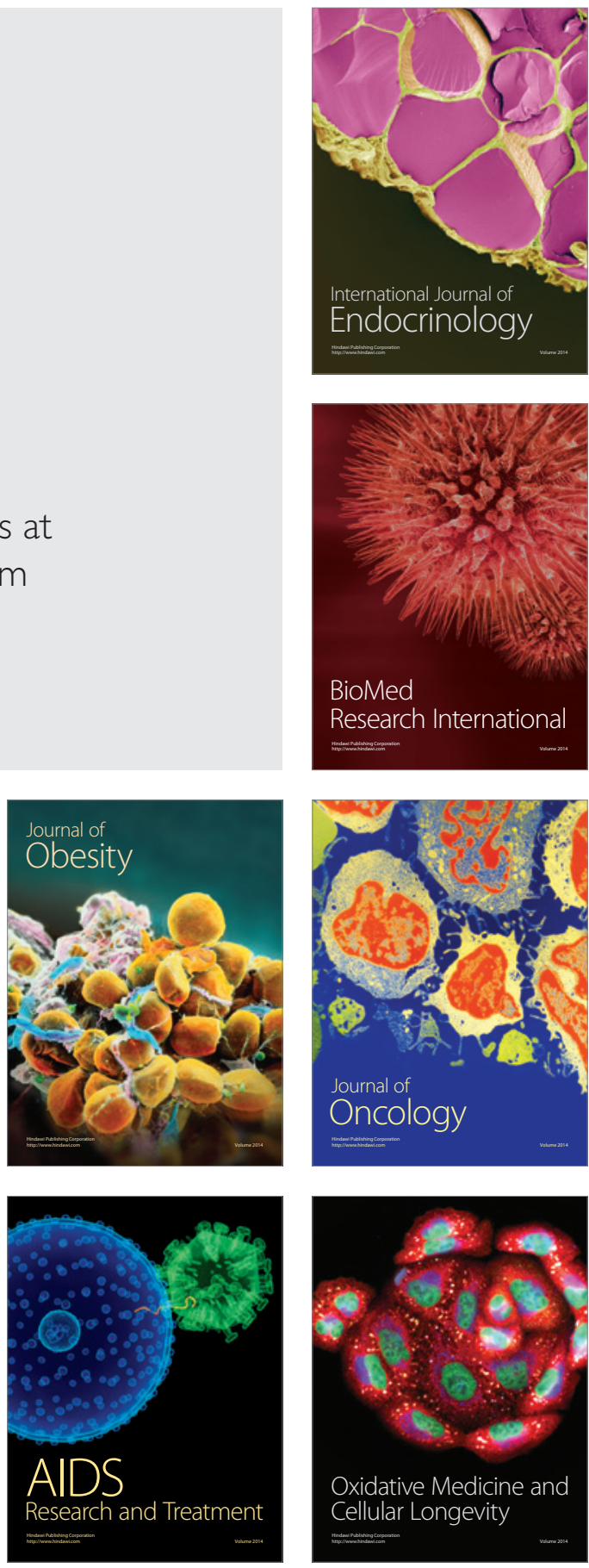